\title{
PRIMARY PERICARDIAL MESOTHELIOMA AN ONCOLOGICAL RARITY
}

\author{
R V Kumar, Avinash, Ramakrishna, Sai Surabhi
}

\begin{abstract}
:
Primary pericardial mesothelioma is a rare and lethal tumor, with a reported prevalence of $<0.002 \%$ [1]. Pleural and pericardial mesotheliomas, which are far more common are usually associated with exposure to asbestos. However, the cause of pericardial mesothelioma is less clear [2] and is influenced by other factors like genetic predisposition, immunological impairment, infection, radiation, dietary factors and recurrent serosal inflammation [3]. Clinical manifestations of the neoplasm include constrictive pericarditis, cardiac tamponade, and heart failure. Because of late presentation and few treatment approaches, primary pericardial mesothelioma carries a poor prognosis. In this paper, we present a case of primary pericardial mesothelioma in a 46 year female presenting as recurrent pericardial effusion along with constrictive pericarditis.

Key Words: pericardial mesothelioma.
\end{abstract}

\section{CASE REPORT:}

A $46 \mathrm{yr}$ female presented with complaints of shortness of breath to a hospital for which she was evaluated and diagnosed and to have pericardial effusion. Pericardial fluid was drained out percutaneously under radiological guidance. The analysis of the pericardial fluid was inconclusive. The patient was relieved of symptoms for nine months on treatment with antitubercular therapy and she again had complaints of shortness of breath with dry cough. She was re-evaluated and diagnosed to be having thickening of pericardial layer along with pericardial effusion. The pericardial effusion was drained and a biopsy of the pericardium was taken. The histopathological examination along with immune histochemistry studies proved it to be a primary pericardial mesothelioma. The patient was then referred to our institute for further management.

On examination of the patient she had complaints of shortness of breath, dry cough, she is hemodynamically

Article received on 26APR 2017, published on 30 APR 2017

R V Kumar ${ }^{1}$, Avinash ${ }^{2}$, Ramakrishna ${ }^{3}$, Sai Surabhi ${ }^{3}$

${ }^{1}$ Professor \& HOD , Department of Cardio Thoracic Surgery,NIMS, India

${ }^{2}$ Senior Resident ,Department of Cardio Thoracic Surgery,NIMS ,India

${ }^{3}$ Assistant Professor Department of Cardio Thoracic Surgery,NIMS, India

Corresponding Author: R V Kumar

Email: rvkumarnims@gmail.com stable. Chest X-ray showed mediastinal widening, Magnetic resonance imaging of the chest revealed thickened pericardium with solid component situated prominently between the aorta and left pulmonary artery with pericardial effusion in the inferior aspect. Cardiac cath study showed diastolic equalization of pressures in the cardiac chambers indicating constrictive pericarditis. So the decision was taken to relieve the constriction as well as to debulk the tumor.

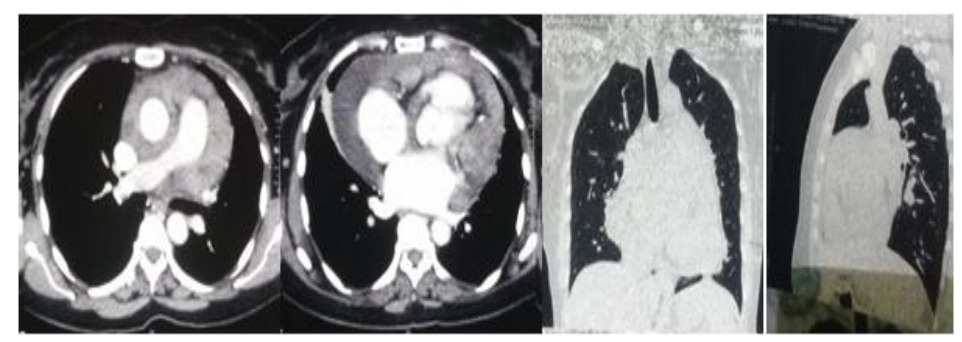

Cardiac MRI and CT Chest showing extension of the tumor between aorta and pulmonary artery, encasing anterior surface of heart.

Intraoperative a thick layer of pericardium about $3 \mathrm{~cm}$ was noted on and around the heart, aorta, pulmonary artery encasing those structures. Tumor was noted to be infiltrating into the left ventricular myocardium. However, bulk of the tumor over the right atrium, right ventricle, aorta and pulmonary vessels was cleared surgically. The tumor tissue is variable in consistency. The central venous pressure came down by 8 to 10 mmHg immediately following the surgery. The excised specimen was sent for histopathological examination. Post surgery patient's shortness of breath improved and patient was referred to a medical oncologist for appropriate chemotherapy.
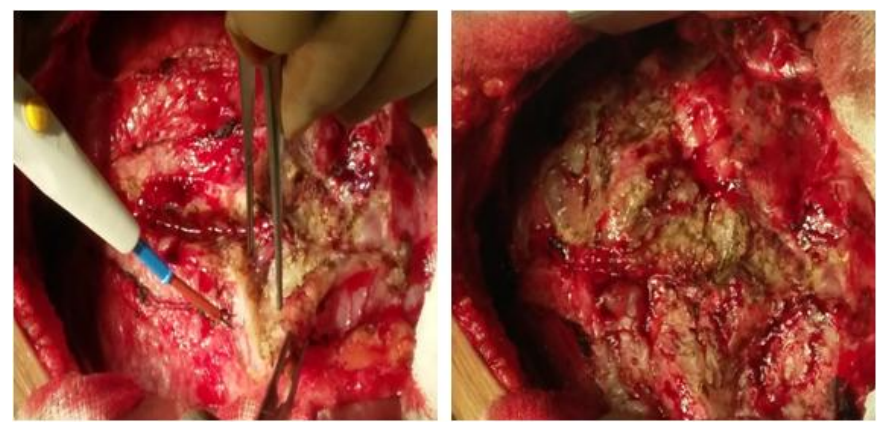


\section{DISCUSSION:}

Mesothelioma is a malignancy deriving from serous epithelial cells of mesothelium. The most frequent sites are pleura and peritoneum. Mesothelioma of the pericardium is extremely rare; they account for $0.7 \%$ of all diagnosed malignant mesotheliomas [4, 5 \& 6]. Primary heart mesothelioma accounts for $2-3 \%$ of all cardiac and pericardial tumors. In a case series of 120 patients, $75 \%$ of the diagnoses were made postmortem, indicating the insidious nature of this highly malignant tumor [7].

Mesothelioma can be localized in the pericardium or it can diffusely encase the heart. It can infiltrate the myocardium (as noted in our case), atria, coronary sinuses, coronary arteries, and the conduction system of the heart. Commonly, the diagnosis is made at an advanced local stage; in one study, metastasis to regional lymph nodes or the lungs was detected in $30 \%$ to $50 \%$ of cases [8]. The tumor can be diagnosed by means of various imaging methods; magnetic resonance imaging provides comparatively better information about the location and extent of the tumor and helps to determine its respectability. As reported in this case, cytologic analysis of pericardial fluid often yields negative results, so diagnosis usually requires tissue for histologic evaluation after surgery or at autopsy [9].

Mesotheliomas can typically cause skin nodules that presented as nodules over chest wall in our case. Pericardial/ peritoneal mesotheliomas presenting as skin nodules over chest and previous appendicectomy scars have been reported $[10,11]$.

Chemotherapy with systemic Adriamycin, Cisplatin with intracavitary administration is of limited success [12]. Improved survival rates have been reported with surgical interventions like pericardectomy. The average median survival time of patients with primary pericardial mesothelioma is 10 months after diagnosis [13]. Newer anticancer approaches like antiangiogenesis drugs, immunomodulator therapies, photodynamic therapy and gene therapy are under trials imparting some hope in future treatment of this dreadful neoplasm [14]. However, as it stands now, surgery alone seems to be the best single modality that provides survival benefit in pericardial mesotheliomas.

\section{REFERENCES}

1. Gossinger HD, Siostrzonek P, Zangeneh M, Neuhold A, Herold C, Schmoliner R, et al. Magnetic resonance imaging findings in a patient with pericardial mesothelioma. Am Heart J 1988; 115(6):1321-2.

2. (Fujiwara H, Kamimori T, Morinaga K, Takeda $\mathrm{Y}$, Kohyama N, Miki Y. An Autopsy case of primary pericardial mesothelioma in arc cutter exposed to asbestos through telc pencils. Industrial Health2005;43: 346-50.)

3. (Rizzardi C, Barresi E, Brollo A, Cassetti P, Schneider M, Melato M. Primary pericardial mesothelioma in an asbestos-exposed patient with previous heart surgery. Anticancer Res 2010; 30(4):1323-5.)

4. (Szczechowski L, Janiec K. Pericardial mesothelioma as very rare cause of reccurent cerebral emboli. Wiad Lek 1992;45: 857-61.

5. Loire R, Tabib A. Malignant mesothelioma of the pericardium: an anatomo-clinical study of 10cases. Arch Mal Coeur Vaiss 1994;87: 255-62.

6. Thomason R, Schlegel W, Lucca M, Cummings S, Lee S. Primary malignant mesothelioma of the pericardium. Case report and literature review. Tex Heart Inst J 1994;21:170-4.

7. (Nambiar CA, Tareif HE, Kishore KU, Ravindran J, Banerjee AK. Primary pericardial mesothelioma: oneyear event-free survival. Am Heart J 1992;124(3):802-3.).

8. (Fazekas T, Tiszlavicz L, Ungi I. Primary malignant pericardial mesothelioma [in Hungarian]. Orv Hetil 1991;132(48): 2677-80).

9. Rizzardi C, Barresi E, Brollo A, Cassetti P, Schneider M, Melato M. Primary pericardial mesothelioma in an asbestos-exposed patient with previous heart surgery. Anticancer Res 2010;30(4):1323-5.

10. Tex Heart Inst J. 2012; 39(2): 261264.PMCID: PMC3384041 Primary Pericardial Mesothelioma Unique Case and Literature Review Muhammad RizwanSardar, MD, Catherine Kuntz, 
MD, Toralben Patel, MD, Wajeeha Saeed, MD, Eric Gnall, DO, ShotaroImaizumi, MD, and Leah Lande, MDJ CutanPathol. 2009 Jun;36(6):675-9. doi: 10.1111/j.16000560.2008.01094.x.Peritoneal mesothelioma presenting as a skin nodule.Abban $\mathrm{C}^{1}$, Viglione $\mathrm{M}$.

11. J, Lowman A, Assey ME. Primary pericardial mesothelioma: diagnostic and therapeutic challenges in management. South Med J 1988;81(4):537-8.
12. Kaul TK, Fields BL, Kahn DR. Primary malignant pericardial mesothelioma: a case report and review. J Cardiovasc Surg (Torino) 1994; 35(3):261-7.

13. Nowak AK, Lake RA, Kindler HL, Robinson BW. New approaches for mesothelioma: biologics, vaccines, gene therapy, and other novel agents. Semin Oncol 2002; 29(1):82-96. 